\title{
某海上 FPSO 生产水处理影响因素及对策分析
}

\author{
Analysis of the Influencing Factors and Countermeasures for \\ Production Water Treatment of FPSO in a Sea \\ 曹贵 李治 张向彬 曾楠诺 王锐
}

Gui Cao Zhi Li Xiangbin Zhang Nannuo Zeng Rui Wang

中海石油(中国)有限公司湛江分公司

中国·广东 湛江 524057

China National Offshore Oil(China) Corporation

Ltd., Zhanjiang Branch,

Zhanjiang, Guangdong, 524057, China
【摘要】某海上 FPSO 作为油田的中心装置, 主要负责接收和处理井口采油平台来液。论 文对该 FPSO 生产水处理现状、处理效果影响因素进行了分析, 并提出相应的对策以及改 进措施, 从而提高生产水排放质量, 减少了原油排海量, 创造了巨大经济效益, 同时有效地 保护了海洋生态环境。

【Abstract】As the central device of oilfield, FPSO is mainly responsible for receiving and processing fluid from wellhead production platform. In this paper, the current status of FPSO water treatment and the influencing factors of treatment effect are analyzed, and corresponding countermeasures and improvement measures are put forward, so as to improve the quality of production water discharge, reduce the huge amount of crude oil discharge in ocean, create great economic benefits, and effectively protect the marine ecological environment.

【关键词】FPSO; 生产水处理; 影响因素; 改进措施; 海洋生态环境

【Keywords】FPSO; production water treatment; influence factors; improvement measures; marine ecological environment

【DOI】10.36012/etr.v2i2.1116

\section{1 引言}

由于上游采油平台原油物性的差异, 某海上 FPSO 生产 处理系统分为轻质处理系统与中质处理系统两个部分, 而生 产水处理系统则公用一套处理系统, 其处理过程分为化学破乳、 重力沉降、离心分离 3 个步骤, 处理方式相对单一简单, 对生 产水的处理有一定的制约，同时该 FPSO 的接收众多井口采 油平台的来液, 由于井口采油平台修井作业频次高、平台药剂 使用种类繁多、海管通球作业频繁以及油田所处海域海况恶劣 等因素的影响,FPSO 生产水达标排放面临着巨大的挑战 ${ }^{[1-3]}$ 。

\section{FPSO 生产水处理现状}

\section{1 生产工艺流程}

某海上 FPSO 生产处理系统分为轻质原油处理系统与中 质原油处理系统两个部分, 轻质原油处理系统设备主要由轻 质一级分离器与轻质二级分离器组成; 中质原油处理系统主 要设备为中质一级分离器 $\mathrm{A} / \mathrm{B}$ 、中质二级分离器、电脱水器; 经过中、轻质原油处理系统分离出来的生产水进入生产水处 理系统, 生产水处理系统主要由 2 个生产水舱、4 台生产水 葲、2 套水力旋流器和改性纤维球装置以及生产水脱气罐组 
成, 经过处理合格的生产水直接排入海里。生产水处理系统其 主要过程分为化学破乳、重力沉降、离心分离 3 个步骤, 整体 来说,生产水处理方式相对单一简单。

\section{2 生产水处理现状}

目前该 FPSO 实际每天接收到的液体总量为 $15130 \mathrm{~m}^{3}$, 生产水为 $11080 \mathrm{~m}^{3}$, 轻质系统 $5264 \mathrm{~m}^{3}$, 中质系统 $5816 \mathrm{~m}^{3}$, 综 合含水率高达 $73.7 \%$, 轻质系统油相密度取 $0.78 \mathrm{~g} / \mathrm{cm}^{3}$, 水相 密度取 $1.02 \mathrm{~g} / \mathrm{cm}^{3}$, 中质系统油相密度取 $0.84 \mathrm{~g} / \mathrm{cm}^{3}$, 水相密 度取 $1.01 \mathrm{~g} / \mathrm{cm}^{3}$ 。轻质一级分离器和中质一级分离器为高效 型油水分离器, 有独立的水室和油室, 其主要依靠调节水室 进水桶的高度, 来控制分离器的油水界面。轻质一级分离器 油水界面为 $2.25 \mathrm{~m}$, 生产水在分离器内停留时间为 $25 \mathrm{~min}$, 中 质一级分离器油水界面为 $2.15 \mathrm{~m}$, 生产水在分离器内停留时 间为 $44 \mathrm{~min}$ 。

两台生产水泵在运行, 生产水泵出口压力 $1.05 \mathrm{MPa}$, 经过 增压后的生产水进入水力旋流器, 通过密度差, 进行进一步的 油水分离, 水力旋流器压差比为 1.8 , 最后经过生产水除气罐 进行简单的沉降, 处理达标后, 直接排海, 生产水泵处理能力 能够达到 $12900 \mathrm{~m}^{3} / \mathrm{d}$, 排海平均含油浓度为 $45 \mathrm{mg} / \mathrm{L}$

\section{3 生产水处理排放要求分类}

中国海域根据 GB 4914-2008《海洋石油勘探开发污染 物排放浓度限值》[4替代 GB 4914-1985 颁布的《海洋石油开 发工业含油污水排放标准》规定划分为:

一级海域:适用于渤海、北部湾, 国家规定的其他海洋保 护区域和其他距最近陆地 4 海里以内的海域;

二级海域:除渤海、北部湾, 国家划定的其他海洋保护区 域外, 其他距最近陆地大于 4 海里而小于 12 海里的海域;

三级海域:适用于一级和二级海区以外的其他海域。

针对不同海域，国家也规定了相应的排放标准，如表 1 所示。

表 1 不同海域生产水排海要求

\begin{tabular}{c|c|c}
\hline 海域 & 月平均值 $/(\mathrm{mg} / \mathrm{L})$ & 一次最大值 $/(\mathrm{mg} / \mathrm{L})$ \\
\hline 一级海域 & 20 & 30 \\
\hline 二级海域 & 30 & 45 \\
\hline 三级海域 & 45 & 60 \\
\hline
\end{tabular}

该 FPSO 生产海域属于三级海域,本着环保至上,生产与 环境和谐发展的原则, 油田一直以来以二级海域排海作为最 低要求，并力争达到一级排放标准。目前排海浓度控制在 $45 \mathrm{mg} / \mathrm{L}$ 以下, 能够达到二级排海要求, 但距离一级海域排放 标准,还存在一定的差距。

\section{3 生产水处理影响因素分析}

对于 FPSO 生产水处理而言，影响其处理效果的因素主 要有: 各设备的处理能力、系统操作温度、在用化学药剂、海管 通球、采油平台的钻修井作业、系统来液变化等,在众多的影 响因素之下,生产水处理也变得异常困难。

\section{1 操作温度的影响}

温度对于生产水处理的影响有如下几个方面:

(1)直接影响分离器中油水的沉降分离, 造成水相含油浓 度偏高, 油相含水不合格, 影响进舱的生产水水质。

(2)影响化学药剂性能的发挥，使用的破乳剂和清水剂都 有特定的使用温度,温度不满足要求, 使得药剂在分离器或者 生产水舱中无法完全发挥其作用。

(3)系统温度较低, 导致原油中重组份析出, 原油流动性能 变差, 造成各仪表附件卡滞, 最为明显就是液位计, 由于液位 计控制戈门开度, 液位计卡滞产生冲击, 造成系统不平稳, 从 而影响进舱的生产水水质。

整个生产系统中, 中质一级分离器设计温度为 $95^{\circ} \mathrm{C}$, 而 实际操作温度为 $65^{\circ} \mathrm{C}$, 轻质一分分离器设计操作温度 $65^{\circ} \mathrm{C}$, 实际操作温度为 $28^{\circ} \mathrm{C}$, 实际操作温度与设计温度相差较远, 特别是轻质处理系统, 在较低的温度情况下, 化学药剂的作用 效果变差, 影响油水的正产分离, 通过数据统计发现轻质一级 分离器的处理工况波动非常大, 水出口含油浓度在 $200 \mathrm{mg} / \mathrm{L}$ 左右,未达到预期的处理效果。

\section{2 在用化学药剂的影响}

油田在用化学药剂种类较多, 化学药剂对于生产水的处 理,主要有以下几方面的影响。

\section{2 .1 化学药剂配伍性}

根据目前数据显示, 中质处理系统缓蚀剂乳化性较强, 海 管通球作业时,缓蚀剂需要提高到 3 倍注入量, 在 3 倍预膜期 间对生产水造成的冲击很大, 同时缓蚀剂和破乳剂配伍性差, 导致一分油相破乳差, 中质二级分离器分及电脱水器频繁跑 油,加大了生产水处理的难度。

\section{2 .2 化学药剂用量的影响}

FPSO 接收多个采油平台来液,各个装置所使用的化学药 剂也存在差异,比如,海管通球之后缓蚀剂 3 倍预膜、破乳剂 䇻选、杀菌剂试验等等,各个装置的药剂注入量变化造成的影 响都会累加到 FPSO, 造成系统处理的不稳定, 从而影响生产 水的处理效果。

\section{3 海管通球的影响}

通球作业会携带海管内部的油泥及杂质进入处理系统,油 
环境工程 Environmental Engineering

泥及杂质在系统中分散造成系统处理效果变差,水出口含油浓 度增加。另外,通球作业过程中产生的段塞流会对生产系统有 一定的冲击, 在分离器内部形成扰动, 造成油水处理效果下降。

\section{4 生产水处理对策及改进措施}

\section{1 新增脱水装置}

针对中轻质系统目前处理量超过设计处理量, 导致生产 水处理效果变差的问题, 目前中质系统上游平台通过新增气 浮选脱水装置, 可直接处理生产水 $2700 \mathrm{~m}^{3} / \mathrm{d}$, 生产水排海平均 含油浓度能降到 $20 \mathrm{mg} / \mathrm{L}$ 以下, 有效减少了 FPSO 生产水处理 量, 增加了生产水在 FPSO 处理系统的停留时间, 液体在一级 分离器的停留时间增加 $3 \mathrm{~min}$, 生产水在生产水舱的停留时间 增加 $5 \mathrm{~min}$, 从而增加了油水依靠重力沉降分离的时间, 油水 分离效果得到改善, 化验结果显示, 生产水排海平均含油浓度 下降 $2 \mathrm{mg} / \mathrm{L}$ 。因此, FPSO 生产水系统可考虑增加生产水处理 装置, 比如, 增加气浮选设备、板式聚结器、过滤罐等深层次生 产水处理设备, 从而改变油田生产水处理方式单一的缺点, 可 有效降低生产水排海含油浓度，同时还能够解决处理设备超 负荷的问题,确保油田安全生产。

\section{2 生产处理系统提温}

由于中轻质系统处理温度均未达到分离器设计温度, 而 轻质系统处理温度为 $28^{\circ} \mathrm{C}$, 远低于轻质一级分离器设计温度 $65^{\circ} \mathrm{C}$, 低温条件下, 油水分离效果明显变差, 轻质一级分离器 水路出口平均含油浓度在 $160 \mathrm{mg} / \mathrm{L}$, 由于轻质系统上游平台 到 FPSO 采用的是单层不保温的海底输油管道，保温效果较 差, 由于海管距离较长, 且海水温度较低, 由于海水的冷却, 导 致输送液体温度急剧下降。温度是生产水处理的关键因素, 提 温主要采取 2 种措施: (1)处理系统增加保温层,减少热量的损 失, 但由于海底管道距离太长, 且作业困难, 作业费用较高, 暂 时不予考虑, 只能通过对裸露在外面的设备增加保温层, 同时 增加电伴热, 从而避免温度的散失。2加热系统提温, 增加加 热系统的运行负荷, 主要是通过投用备用的热介质锅炉, 同时 提高热介质锅炉的温度设点, 从而整体提高加热系统的运行 温度。从而提高生产水的处理效果。

\section{3 优选化学药剂}

FPSO 主要依靠破乳剂的化学破乳作用, 能够有效地进行 油水分离, 而清水剂能使生产水中有机小颗粒絮凝成为较大 的有机颗粒, 从而使之沉降下来, 达到进化污水的目的。化学 药剂对生产水的处理有着至关重要的作用, 化学药剂主要从 选择和使用入手, 定期化验记录流体物性参数, 根据流体物性 参数以及现场工况, 对化学药剂进行测试笁选工作, 药剂厂商
在上油田做实验前, 提前做好室内药剂配伍性评价, 避免化学 药剂之间相互影响, 上油田后提供药剂配伍性报告。现场试验 过程中, 确保工况一致, 保证药剂篮选时无其他干扰项, 确保 实验报告真实有效。对比不同药剂厂家生产水处理效果, 选择 最适宜油田工况的化学药剂。

\section{4 根据工况优化工艺参数}

开展生产处理系统适应性排查, 根据设备运行情况, 优化 设备工艺参数, 确保设备处于平稳高效运行的状态。

当上游平台工作制度发生改变时, 及时通知 FPSO, 做好 相应的应对措施, 及时调整药剂注人浓度, 同时做好数据收 集、统计、记录工作,摸索变化规律。

当平台要进行通球作业以及有钻修井液体进入生产处理 系统时, FPSO 提前降低生产水舱液位, 生产水提前进行回舱 处理, 确保生产水有足够的沉降时间, 同时根据量舱结果, 定 期对生产水舱进行溢流, 定期对各分离器进行冲砂作业, 避免 大量的杂质进入生产处理系统, 对生产处理系统造成冲击, 从 而造成生产水排放不达标。

针对水力旋流器, 继续做提高单台水力旋流器入口压力 实验, 判断进口压力与水力旋流器效率之间的关系, 确定水力 旋流器最合适的压差比, 推动改造目前生产水泵到水力旋流 器的人口管网流程, 减少管损, 定期清洗水力旋流管, 选择除 油效率比较高的旋流管, 从而提高水力旋流器的除油效率。

\section{5 结论}

(1)新增脱水装置, 可以有效解决设备超负荷的问题, 同时 生产水排海平均含油浓度可降低 $20 \mathrm{mg} / \mathrm{L}$, 同时可改变生产水 系统处理方式单一抗干扰能力弱的不足。

(2)在现有加热系统基础上, 对处理系统提温, 生产水处理 效果没有明显改善, 反而增加系统运行负荷, 影响安全生产。

(3)通过优选化学药剂以及确定化学药剂的注人浓度, 可 有效地提升生产水处理效果。

(4)对平台井液进行摸排, 查明轻质系统乳化程度改变的 原因并采取相应措施, 优化相应的工作制度, 可以从源头上保 证生产水的质量。

\section{参考文献}

[1]蒋克涁.污水处理工艺与应用[M].北京: 中国石化出版社,2014.

[2]李宝彦,李淑华.改性纤维球过滤技术的研究与应用[J].石油化 工设备.2008,25(1):34-35.

[3]屈撑囤,杨鹏辉,李彦.油气田含油污水处理技术 $[\mathrm{M}]$. 北京:石油 工业出版社,2015.

[4]GB 4914-2008 海洋石油勘探开发污染物排放浓度限值[S]. 